\title{
Initial Teacher Education and the development of teacher identity
}

\author{
Donella J Cobb \\ Division of Education, The University Waikato, Hamilton, New Zealand \\ $\triangle$ donella.cobb@waikato.ac.nz
}

\section{Introduction}

Teacher identity is recognized as an important factor in teacher quality. Research indicates that teacher identity influences teachers' resilience, efficacy, motivation, commitment, and job satisfaction (Day, 2018). However, widespread interest in the field of teacher identity has also revealed the importance of developing teacher identity prior to entry into the teaching profession. Pre-service teachers who develop teacher identity during their teacher preparation program actively strengthen their pedagogical content knowledge, develop an early understanding of the teachers roles and responsibilities, build positive relationships with students and colleagues, and are motivated to enhance their teaching practice (Cobb, Harlow, \& Clark, 2018; Harlow \& Cobb, 2014). Furthermore, teacher identity is also believed to be a key factor in supporting pre-service teachers' transition into the teaching profession. Given these benefits, the past decade has seen an explosion of interest in understanding identity development, particularly in pre-service teachers. This entry explores how teacher identity is developed in pre-service teachers and considers the role that Initial Teacher Education (ITE) plays in supporting this identity development.

\section{The development of teacher identity}

Despite widespread recognition of the importance of developing teacher identity in preservice teachers, research is yet to provide a clear and comprehensive understanding of how teacher identity is formed and developed over time. What is evident is that teacher identity is developed through the merging of the professional and personal self. This dynamic and ongoing process involves the interaction between personal biographies, life histories, agency, efficacy and the social and political environment in which one is located (Buchanan \& Olsen, 2018). It also involves a process of internal validation where pre-service teachers make sense of themselves within this professional role. This occurs when pre-service teachers recognize themselves within the full range of professional roles, responsibilities, capabilities and capacities that teaching entails. For this reason, the internal stories that pre-service teachers tell themselves are an important part of identity construction.

Alongside this process of self-verification, identity development also requires validation from significant others. Teacher identity is a socially constructed phenomenon and, therefore, other teachers, peers, parents and students all play a role in affirming pre-service teachers' sense of 'teacher self' (Cobb et al., 2018). Yet, despite this process of external and internal validation, teacher identity tends to be unstable. Identities are formed and reformed, shaped and reshaped as pre-service 
teachers work within the fluid and dynamic nature of educational contexts (Day, 2018). Because of this, identity development is a continual, dynamic and fluctuating process.

The relationship between identity, agency and environment is central to identity development. Identity-agency is a particular form of agency that requires individuals to draw personal experiences from their participation within a learning environment to negotiate, transform or defend their teacher identities (Ruohotie-Lyhty, 2018). In other words, identity-agency mediates between ones own identity and wider environmental influences. For example, when pre-service teachers exercise identity-agency within a particular social context, such as the teaching practicum, they interpret their experiences as a teacher, and this helps them make sense of themselves within this professional role (Cobb et al., 2018). Active investment within a social context is essential to this shaping and reshaping of their identities. This is especially the case for pre-service teachers, as they are often positioned within multiple and temporal practicum contexts throughout the duration of their Initial Teacher Education (ITE) program. For this reason, their ability to exercise identity-agency is a key negotiating factor in identity development.

There are three ways that identity-agency can author teacher identities (RuohotieLyhty, 2018). Each of these responses involves a process through which identities are either; 1) renegotiated through additive measures, 2) renegotiated through transformative measures, or 3) defended. For example, when faced with situations that challenge pre-service teachers conceptualization of their professional self, identityagency enables them to either renegotiate their identities in light of this new information, or defend their identities by resisting these influences (Ruohotie-Lyhty, 2018). This requires continual negotiation or renegotiation of their internal storying as pre-service teachers work to either conceptualize or re-conceptualize their identities. Renegotiating identities: additive development occurs when there is a close match between the original identity and the environment. This close alignment requires minimal transformation on the pre-service teachers' part as they integrate practices and principles that already closely align to their original identity. Renegotiating identities: transformative development occurs when there is a mismatch between a pre-service teachers' identity and expectations within the environment. This requires pre-service teachers to renegotiate their identities to align with these environmental expectations. This is a demanding process of identity transformation and necessitates a significant internal shift. Finally, defended identities occurs when there is a significant mismatch between identity and environmental expectations however, in this case, the individual refuses to renegotiate their identity. This resisitance is seen in the rejection of the environmental demands and, in some cases, may lead to a pre-service teacher leaving the environment or attempting to transform the environment to achieve alignment with their identity. This model of identity authoring demonstrates how identity-agency is a central factor in identity development. It also draws attention to the importance of teacher preparation programmes in supporting pre-service teachers to exercise identityagency.

\section{The role of Initial Teacher Education in identity development}

Initial Teacher Education (ITE) plays an important role in supporting the development of teacher identity in pre-service teachers. Teacher preparation programs generally contain both theoretical and practical components, with the teaching practicum 
providing an opportunity for pre-service teachers to engage in a period of sustained teaching experience prior to their entry into the teaching profession. The professional experience component of an ITE program is an important aspect of identity development. However, the time allocated to professional experience during ITE, and its' impact on identity development has been a subject of much interest and considerable debate. Some ITE providers schedule blocks of time, ranging from one week to one semester, for teaching experience practicum. In this model, pre-service teachers generally complete several practicums in different learning contexts and for varying blocks of time throughout the duration of their ITE program. Other programs timetable regular placement days over a sustained period of time (such as a semester or academic year). More recently, there has been a rise in practice based teacher education programs where, much like an apprenticeship, pre-service teachers complete the majority of their teacher preparation in the classroom under the guidance of an associate teacher/mentor. While there is no clear or conclusive answer to the question of how much time is sufficient to develop teacher identity, what is clear is that the quality of professional experience has a strong influence on identity development. Factors such as the relationship between pre-service teachers and their associate/mentor teacher, and the degree of agency pre-service teachers can exert within this relationship have been examined to understand their contribution to identity development.

The relationship between pre-service teacher and their associate/mentor teacher has a significant influence on pre-service teachers' identity development (Cobb et al., 2018). Central to this relationship is the degree to which pre-service teachers are afforded agency to enact their identities. Tensions arise when associate/mentor teachers expect pre-service teachers to replicate their own teaching practices, behaviors, beliefs, values and identities. Identity clashes can occur when pre-service teachers actively resist or seek to transform the expected enactment of their associate/mentor teachers' identities. This tension is further exacerbated by the practicum assessment, which frequently places the associate/mentor teacher in the dual role of mentor and assessor. Because this assessment is high stakes, some pre-service teachers neglect their own identity development to assimilate with their associate/teachers identities. Given the centrality of identity-agency to identity development, pre-service teachers who are restricted in their ability to enact their identities may not sufficiently experience, explore and develop who they are as teachers prior to entry into the teaching profession. In contrast, pre-service teacher who have the opportunity to exercise identity-agency in their practicum conclude their teacher preparation program with a stronger sense of teacher self (Cobb et al., 2018).

Another factor in this associate/mentor teacher relationship that contributes to the development of teacher identity is external validation. Associate/mentor teachers play a leading role in affirming that pre-service teachers' identities are indeed valid, valued and legitimate. This is especially important for pre-service teachers who are beginning to enact their internal stories of who they are as teachers. Other teachers in the school, ITE practicum evaluators, children and parents can also provide a source of external validation, however it is this relationship with their associate/mentor teacher that seems to be particularly influential. Without this validation, pre-service teachers can find it difficult to see themselves in the role of a teacher (see Cobb et al., 2018). Identities are supported and strengthened when associate/mentor teachers provide regular feedback so pre-service teachers have the opportunity to confirm, renegotiate or defend their emerging identities. 
A further reason why practicum is so important for identity development is because it enables pre-service teachers to engage in the roles and responsibilities of teaching. Preservice teachers' begin their teacher preparation programs with well-formed internal images of what they believe it means to be a teacher. Their emerging identities are crafted around these conceptualizations of what they believe teachers do and the roles and responsibilities that they believe teachers perform. Practicum provides pre-service teachers with a context to experience some of the facets of teachers' work. For some, these roles closely match their own image of teachers' work and their foundation on which their identities have been shaped. For others, their practicum experiences reveal a mismatch between their internal imaging of the nature of teachers' work and the realities of teaching (Ruohotie-Lyhty, 2018). This requires pre-service teachers to engage in a process of renegotiating, reshaping and transforming their identities to more closely align with the realities of teaching. However, there is concern that the teaching practicum creates false realities for pre-service teachers by obscuring them from the full breadth of teachers work (Buchanan \& Olsen, 2018). There are some aspects of teachers' work, such as taking responsibility for assessments, reporting to parents, engaging with external services, and responding to the political influences on teaching, that may not be possible for pre-service teachers to experience during their professional experience program. This is seen as a contributing factor for the high attrition rate in early career teachers as this process of renegotiating and transforming their identities to respond to these previously obscured responsibilities can be demanding.

However, professional experiences programs are not the only factor that supports identity formation in pre-service teachers. ITE coursework also plays a pivotal role. Coursework provides opportunities for pre-service teachers to critically reflect on their life histories, past educational experiences, their personal image of teaching and emerging teacher identity. Furthermore, ITE programs can involve pre-service teachers in the critical examination of theory, policy and practice in a way that seeks to achieve transformative teaching practice by challenging discriminatory ideologies and power relations. This theoretical basis is important during identity development to achieve wider transformative change. With this in mind, there is growing concern that an increasing focus on practice based teacher education programs has led to an overemphasis on the practice of teaching and an under-emphasis on theoretical development (Buchanan \& Olsen, 2018). Models that conceptualize teacher development as a transmissive process tend to structure their teacher preparation programs on practical experience under the guidance of a mentor/associate teacher. However critics maintain that such approach can lead to the uncritical replication of ineffective teaching practices, and this can have a detrimental influence on the development of teacher identity (Buchanan \& Olsen, 2018). For this reason, the combination of both theory and practice in ITE programs is considered to be the most effective in identity development.

Achieving greater synergy between theory and practice has seen the recent emergence of collaborative partnerships between ITE providers and local schools/ECE centers. While there are variations in how these partnerships operate, generally speaking, ITE providers and schools/ECE centers work collaboratively to create a community of practice to teach and assess pre-service teachers throughout the duration of their teacher preparation program (see Harlow \& Cobb, 2014). In some instances, pre-service teachers are placed in the same school/ECE center for an extended period of time (e.g. one academic year). During this time, pre-service teachers have regular weekly 
placement days with the same associate/mentor teacher, which is followed by a practicum in the same school. Teachers and ITE lecturers work collaboratively to design, teach and assess course content, which creates greater synergy between theory and practice. While research on identity development in collaborative partnership programs is still an emerging field, initial findings suggest that this collaborative partnership model is effective in nurturing, and sustaining, identity development (Cobb et al., 2018; see Harlow \& Cobb, 2014). With this in mind, collaborative partnerships between ITE providers and schools/ECE centers may provide a structural model that effectively supports the early development of teacher identity in pre-service teachers.

\section{References}

Buchanan, R., \& Olsen, B. (2018). Teacher identity in the current teacher education landscape. In P. A. Schutz, J. Hong, \& D. Cross Francis (Eds.), Research on teacher Identity: Mapping challenges and innovations (pp. 195-206). Cham, Switzerland: Springer. Retrieved from https://doi.org/10.1007/978-3-31993836-3_17

Cobb, D. J., Harlow, A., \& Clark, L. (2018). Examining the teacher identity-agency relationship through legitimate peripheral participation: A longitudinal investigation,. Asia-Pacific Journal of Teacher Education, 46(5), 495-510. https://doi.org/10.1080/1359866X.2018.1480010

Day, C. (2018). Professional identity matters: Agency, emotions, and resilience. In P. Schutz, J. Hong, \& D. Cross Francis (Eds.), Research on teacher identity: Mapping challenges and innovations (pp. 61-70). Cham, Switzerland: Springer. Retrieved from https://doi.org/10.1007/978-3-319-93836-3_6

Harlow, A., \& Cobb, D. J. (2014). Planting the seed of teacher identity: Nurturing early growth through a collaborative learning community. (Online), 39(7), 70. Australian Journal of Teacher Education, 39(7), 70-88.

Ruohotie-Lyhty, M. (2018). Identity-agency in progress: Teachers authoring their identities. In P. . Schutz, J. Hong, \& D. Cross Francis (Eds.), Research on teacher identity, (pp. 25-36). Switzerland, Cham: Springer. Retrieved from https://doi.org/10.1007/978-3-319-93836-3_3 